\title{
Antitumor activity of CDA-II, a urinary preparation, on human multiple myeloma cell lines via the mitochondrial pathway
}

\author{
MIN YANG, JIAN HUANG, QIU-LING MA, GAI-XIANG XU and JIE JIN \\ Department of Hematology, Institute of Hematology, The First Affiliated Hospital of \\ Zhejiang University, School of Medicine, Hangzhou, Zhejiang, P.R. China
}

Received June 1, 2013; Accepted September 20, 2013

DOI: $10.3892 / \mathrm{mmr} .2014 .1911$

\begin{abstract}
Cell differentiation agent II (CDA-II) is a DNA methyltransferase inhibitor isolated from healthy human urine. In the present study, the antitumor activity of CDA-II on human multiple myeloma (MM) cell lines via the mitochondrial pathway was first revealed. The human MM cell lines were exposed to CDA-II. Cytotoxicity, caspase activation, apoptosis and the effects on the mitochondrial pathway were assessed. CDA-II was capable of decreasing the depolarized mitochondrial membranes and activating caspase-3 and -9 and poly (ADP-ribose) polymerase in MM cells treated with CDA-II. CDA-II induced caspase-dependent cell death accompanied by a significant decrease in X-linked inhibitor of apoptosis protein (XIAP), survivin and Mcl-1 levels. The caspase-3 inhibitor, Z-DEVD-FMK, inhibited CDA-II-induced apoptosis. CDA-II potently increased the Bax levels, decreased the Bcl-2/Bax ratio and decreased the expression of the downstream targets of NF- $\kappa \mathrm{B}$. In conclusion, the results of the present study demonstrated that CDA-II treatment leads to the inhibition of p65 nuclear localization and potently induces caspase-dependent apoptosis in MM cells mediated through the mitochondrial pathway at low nanomolar concentrations. These results indicate that CDA-II is a novel inhibitor of NF- $\kappa \mathrm{B}$ activity, with notable antimyeloma efficacy. This study provides a rationale for the clinical investigation of CDA-II in human MM.
\end{abstract}

\section{Introduction}

Multiple myeloma (MM) is characterized by a latent accumulation of secretory plasma cells with a low proliferative

Correspondence to: Professor Jie Jin, Department of Hematology, Institute of Hematology, The First Affiliated Hospital of Zhejiang University, School of Medicine, 79 Qingchun Road, Hangzhou, Zhejiang 310003, P.R. China

E-mail: zjuhematology@163.com

Key words: cell differentiation agent II, antitumor activity, multiple myeloma, mitochondrial pathway index and an extended life span in the bone marrow. MM is the second most prevalent hematological cancer after non-Hodgkin lymphoma, accounting for $10 \%$ of all hematological cancers and $2 \%$ of all cancer mortalities. More significantly, MM has a higher frequency in elderly individuals. Despite conventional therapies with proteasome inhibitors, thalidomide analogs, alkylating agents, anthracyclines and corticosteroids (1), as well as high-dose therapy and stem cell transplantation $(2,3)$, MM remains incurable due to intrinsic and acquired drug resistance (4-6). The cytotoxicity of the current treatment limits the clinical effect, particularly for older patients, and the acquisition of drug resistance remains a severe problem. Therefore, novel therapeutic strategies are urgently required.

The use of urine and urine extracts for therapeutic purposes has been known for centuries (7-9). In previous years, Burzynski (7) and scientists elsewhere in the world (10) demonstrated the anticancer effects of these urine extracts. Cell differentiation agent II (CDA-II) is a mixture, isolated from healthy human urine which is produced only China. Multiple active components have been shown to act concurrently with different mechanisms of action to contribute to the anticancer effect of CDA-II (11). CDA-II has been demonstrated to act as a novel anticancer agent having multiple biological targets in the aspects of antiproliferation, apoptosis, differentiation and gene regulation in several solid tumors (12-13). CDA-II has been applied to the treatment of various cancer cells, including glioma (14) and breast cancer (15) cells. CDA-II may protect normal cells from oxidative (9) and DNA (16) damage, and also may affect skeletal myogenesis (17). However there have been no studies on the use of CDA-II antitumor activity to treat MM.

\section{Materials and methods}

Chemicals. CDA-II was supplied by Everlife Pharmaceutical Co., Ltd. (Hefei, China). Briefly, human urine was acidified during collection and passed through an ultrafiltration process to remove molecules with molecular weights of $>10,000 \mathrm{Da}$. The filtrate was then passed through a chromatographic column and eluted by ethanol. The colored ethanolic fraction was collected and evaporated under a vacuum. The dried extract was reconstituted with distilled water to produce a $300 \mathrm{mg} / \mathrm{ml}$ stock solution and stored 
at $4{ }^{\circ} \mathrm{C}$. The 3-(4,5-dimethylthiazol-2-yl)-2,5-diphenyltetrazolium bromide (MTT; Sigma, St. Louis, MO, USA) was dissolved in RPMI-1640 media to produce a $5 \mathrm{mg}$ / $\mathrm{ml}$ solution. The caspase-3 inhibitor, Z-DEVD-FMK (40 $\mu \mathrm{mol} / \mathrm{l}$; BioVision, Milpitas, CA, USA), was added $1 \mathrm{~h}$ prior to treatment with CDA-II. Primary antibodies included caspase-3, poly (ADP-ribose) polymerase (PARP), caspase-9, $\mathrm{X}$-linked inhibitor of apoptosis protein (XIAP) (all rabbit; all BioVision, Mountain View, CA, USA), actin (goat; Santa Cruz Biotechnology, Inc., Santa Cruz, CA, USA), Bcl-2 (rabbit), Bax (mouse), Mcl-1 (rabbit) and survivin (rabbit) antibodies (Cell Signaling, Danvers, MA, USA). Horseradish peroxidase-conjugated secondary anti-mouse and anti-rabbit antibodies were purchased from Santa Cruz Biotechnology, Inc. Enhanced chemiluminescence western blotting detection reagents were purchased from Amersham Biosciences (Little Chalfont, UK). The mitochondrial fluorescent probe, 5,5',6,6'-tetrachloro-1,1',3,3'-tetraethylbenzimidazol-carbocyanine iodide (JC-1), was purchased from Molecular Probes (Eugene, OR, USA).

Cell culture. The U266, RPMI8226, MM.1R and MM.1S cell lines were maintained in RPMI-1640 (Gibco-BRL, Carlsbad, CA, USA) supplemented with $10 \%$ heat-inactivated fetal calf serum (Gibco-BRL), $0.2 \mathrm{mg} / \mathrm{ml}$ streptomycin/penicillin and $0.1 \%(\mathrm{w} / \mathrm{v})$ L-glutamine (Gibco-BRL) in a $5 \%$ humidified $\mathrm{CO}_{2}$ atmosphere at $37^{\circ} \mathrm{C}$. The MM cell lines, RPMI8226 and U266, were obtained from the American Type Culture Collection (Rockville, MD, USA). MM.1R and MM.1S cells were provided by Professor Steven Rosen (Northwestern University, Chicago, IL, USA). Hypaque gradients were run to obtain normal peripheral blood mononuclear cells (PBMCs). All the healthy volunteers approved use of their samples.

Cytotoxicity assay. The cells were seeded at a density of 10,000 per well in 96-well microtiter plates. The cells were treated with various concentrations of CDA-II and incubated at $37^{\circ} \mathrm{C}$ in a $5 \% \mathrm{CO}_{2}$ atmosphere for $48 \mathrm{~h}$. Subsequently, $20 \mu \mathrm{l}$ MTT (Sigma) stock solution was added to each well (final concentration: $0.5 \mathrm{mg} / \mathrm{ml})$ for another 4 -h incubation $\left(37^{\circ} \mathrm{C}\right.$ and $5 \% \mathrm{CO}_{2}$ ). Following $4 \mathrm{~h}$ of incubation, $200 \mu \mathrm{l}$ dimethylsulfoxide was added to each well and the optical density was read at $570 \mathrm{~nm}$. The sensitivity of cells to CDA-II was measured by the $\mathrm{IC}_{50}$ (50\% inhibitory concentration). The experimental conditions were analyzed in sextuplicate (six wells of the 96-well plate per experimental condition). All the experiments were performed in triplicate.

Flow cytometric analysis for apoptosis. Human MM cell lines in the exponential growth phase were incubated at $5 \times 10^{5}$ cells $/ \mathrm{ml}$ on six-well flat-bottomed microplates in RPMI-1640 medium supplemented with $10 \%$ fetal calf serum in the presence of $4 \mathrm{mg} / \mathrm{ml} \mathrm{CDA-II} \mathrm{for} \mathrm{0-24} \mathrm{h.} \mathrm{Apoptosis} \mathrm{was}$ measured by Annexin $\mathrm{V}$ and propidium iodide (PI) staining. Briefly, the cells were harvested, washed with PBS [10 mmol/1 $N$-2-hydroxyl piperazine- $N$ '-2-ethane sulfonic acid/ $\mathrm{NaOH}(\mathrm{pH}$ 7.4), $140 \mathrm{mmol} / \mathrm{l} \mathrm{NaCl}$ and $2.5 \mathrm{mmol} / 1 \mathrm{CaCl}_{2}$ ], incubated with $10 \mu 1$ Annexin V-fluorescein isothiocyanate (Pharmingen, Immunocytometry System, San Jose, CA, USA) and $10 \mu 1$ PI $(10 \mu \mathrm{g} / \mathrm{ml}$ in binding buffer) in the dark for $15 \mathrm{~min}$, and assayed following the addition of $300 \mu \mathrm{l}$ binding buffer to each sample. The data acquisition and analysis were conducted on a BD FACS caliber (Becton-Dickinson, Franklin Lakes, NJ, USA) using CellQuest software (Becton-Dickinson). Annexin $\mathrm{V}$ bound to those cells that expressed phosphatidylserine on the outer layer of the cell membrane, and PI stained the cellular DNA of those cells with a compromised cell membrane. All the experiments were performed in triplicate.

JC-1 stain for mitochondrial membrane potential $(\Delta \psi m)$. Alterations in the $\Delta \psi \mathrm{m}$ were analyzed by flow cytometry using the $\Delta \psi \mathrm{m}$-sensitive dye, JC-1. Briefly, following treatment, $2 \times 10^{6}$ cells were harvested, washed once and then resuspended in phosphate-buffered saline (PBS), prior to incubation with $1 \mu \mathrm{mol} / 1 \mathrm{JC}-1$ at $37^{\circ} \mathrm{C}$ for $10 \mathrm{~min}$. The stained cells were then washed once in PBS and analyzed by flow cytometry. A BD FACS caliber (Becton-Dickinson) was used to analyze a minimum of $1 \times 10^{4}$ cells per sample. JC- 1 is a cationic dye that exhibits potential-dependent accumulation in mitochondria, indicated by a fluorescence emission shift from green $(525 \pm 10 \mathrm{~nm})$ to red $(610 \pm 10 \mathrm{~nm})$. The data were evaluated using a CellQuest software package (Becton-Dickinson). The forward and side scatter were used to gate the viable populations of cells. JC-1 monomers emit at $527 \mathrm{~nm}$ (FL-1 channel) and 'J-aggregates' emit at $590 \mathrm{~nm}$ (FL-2 channel). All the experiments were performed in triplicate.

Western blotting. The human MM cells were incubated with $4 \mathrm{mg} / \mathrm{ml} \mathrm{CDA-II}$ for $12 \mathrm{~h}$. The cells $\left(5 \times 10^{6}\right)$ were harvested and lysed in $200 \mu 1$ lysis buffer [0.5 M Tris- $\mathrm{HCl}$ (pH 6.8), $2 \mathrm{mM}$ EDTA, $10 \%$ glycerol, $2 \%$ SDS and 5\% $\beta$-mercaptoethanol]. In total, $40 \mu \mathrm{g}$ per lane of the extracted total protein was loaded on $12 \%$ Tris-glycine gels and then transferred to a polyvinylidine difluoride membrane (Millipore, Billerica, MA, USA). The membrane was blocked in 5\% skimmed milk dissolved in Tris-buffered saline with $0.1 \%$ Tween-20, and subsequently probed with the primary antibody and horseradish peroxidase-labeled secondary antibody. The bands were visualized using enhanced chemiluminescence western blotting detection reagents. All the experiments were performed in triplicate and the proteins were normalized against actin prior to analysis.

Statistical analysis. All values are presented as the mean \pm standard deviation. The differences between the two groups were analyzed by unpaired Student's t-test. $\mathrm{P}<0.05$ was considered to indicate a statistically significant difference.

\section{Results}

Effect of CDA-II on the growth of MM cell lines independent of IL-6. To investigate the effects of CDA-II on the growth and survival of human MM cells, four human MM cell lines, RPMI8226, U266, MM.1R and MM.1S, and tumor cells from MM patients were treated. The dose-response curves are shown in Fig. 1A. All the cells exhibited a dose-dependent sensitivity to CDA-II $(0-16 \mathrm{mg} / \mathrm{ml})$ at $24 \mathrm{~h}$. The CDA-II $\mathrm{IC}_{50}$ for the RPMI8226, U266, MM.1R and MM.1S cell lines were $2.90,3.53,4.23$ and $2.68 \mathrm{mg} / \mathrm{ml}$, respectively. CDA-II also induced dose-dependent cytotoxicity in the tumor cells from three de novo $\mathrm{MM}$ patients, with an $\mathrm{IC}_{50}$ at $24 \mathrm{~h}$ of 4.97 , 
A

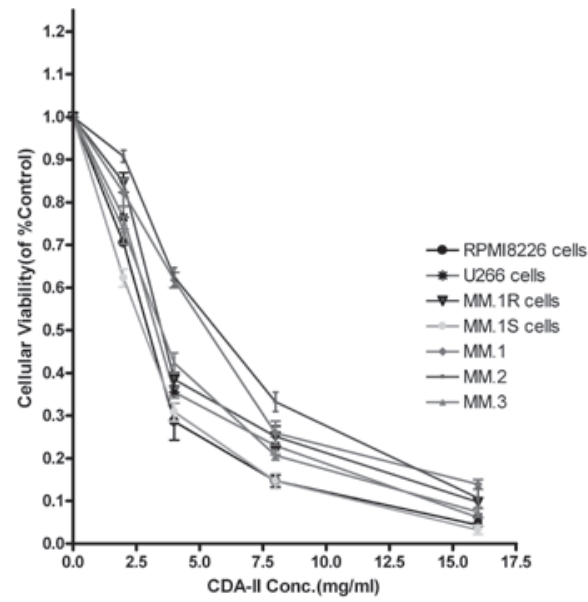

B

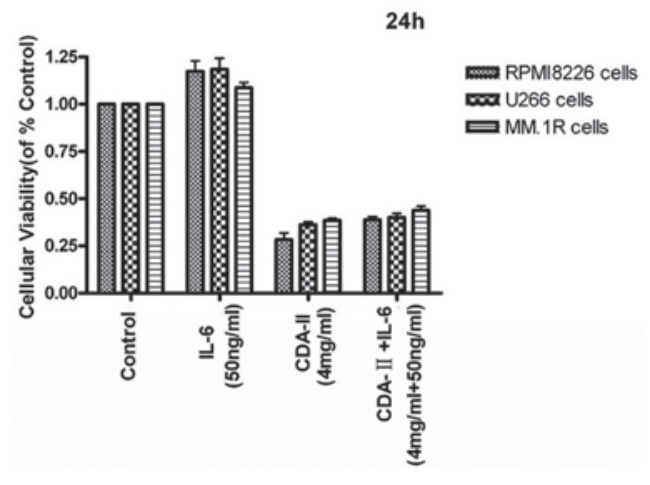

Figure 1. (A) Four types of human multiple myeloma (MM) cell lines were treated with CDA-II (2-16 g/l) for $24 \mathrm{~h}$ and the cytotoxicity was analyzed by an MTT assay. Cell survival was expressed as the optical density ratio of the treatment to the control. CDA-II exhibited cytotoxicity in a dose-dependent manner in RPMI8226, U266, MM.1R and MM.1S cells. The data represent the mean \pm SD of three independent experiments. (B) RPMI8226, U266, MM.1R and MM.1S cells were treated with CDA-II $(4 \mathrm{mg} / \mathrm{ml})$ in the presence or absence of IL-6 $(50 \mathrm{ng} / \mathrm{ml})$. At $24 \mathrm{~h}$, the cells were harvested and the viability was analyzed by MTT assay. The median viability of the RPMI8226 cells treated with CDA-II and IL-6 was 28.28 and $117.30 \%$, respectively, at 24 h, whereas that of cells treated with CDA-II + IL-6 $(4 \mathrm{mg} / \mathrm{ml}, 50 \mathrm{ng} / \mathrm{ml})$ was $61.19 \%(\mathrm{P}<0.01)$. The median viability of the U266 cells treated with CDA-II and IL-6 was 36.20 and $118.67 \%$, respectively. IL-6 enhances the growth of cells at $24 \mathrm{~h}$. The median viability of cells treated with CDA-II + IL-6 was $39.96 \%$ (P<0.01). The results are expressed as the mean \pm SD of three independent experiments. While the median viability of MM.1R cells treated with CDA-II and IL-6 was 38.49 and $108.67 \%$, respectively, at $24 \mathrm{~h}$, that of cells treated with CDA-II + IL-6 (4 mg/ml, $50 \mathrm{ng} / \mathrm{ml})$ was $43.82 \%$ (P<0.01). The median viability of the MM.1S cells treated with CDA-II and IL-6 was 30.88 and $130.33 \%$, respectively, at $24 \mathrm{~h}$, and that of the cells treated with CDA-II + IL-6 (4 mg/ml, $50 \mathrm{ng} / \mathrm{ml})$ was $33.94 \%(\mathrm{P}<0.01)$. The bars represent the mean \pm standard error of the mean $\left(\mathrm{n}=3,{ }^{*} \mathrm{P}<0.01\right.$ vs. control). CDA-II, cell differentiation agent II; MTT, 3-(4,5-dimethylthiazol-2-yl)-2,5-diphenyltetrazolium bromide; SD, standard deviation; IL-6, interleukin-6.
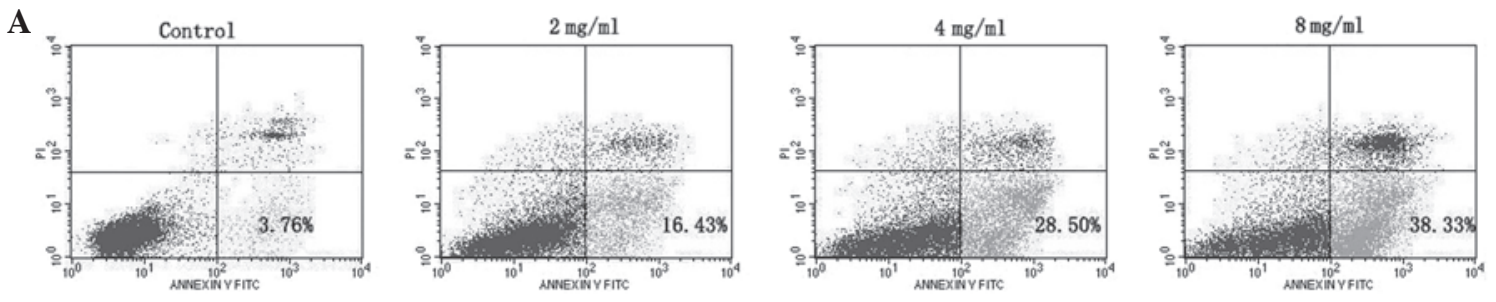

B

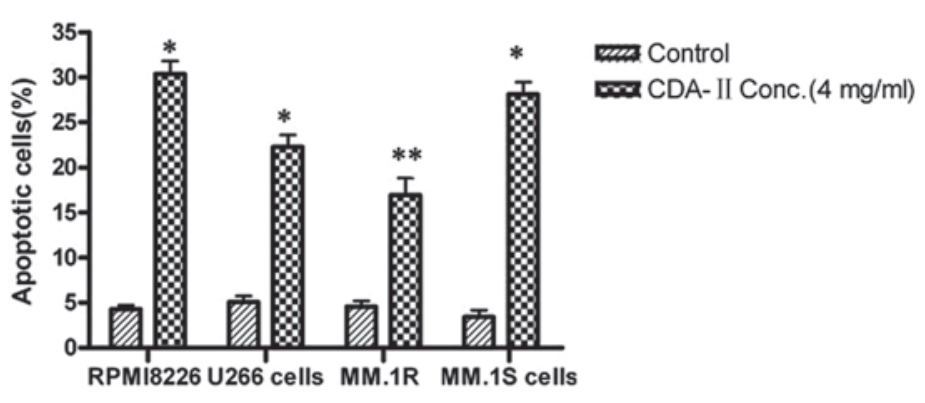

Figure 2. (A) RPMI8226 cells incubated with the indicated concentrations of CDA-II for $12 \mathrm{~h}$ were stained for flow cytometric analysis. The early apoptotic cells increased in a dose-dependent manner. (B) The human MM ROMI8226, U266, MM.1R and MM.1S cells were all incubated with $4 \mathrm{mg} / \mathrm{ml} \mathrm{CDA-II} \mathrm{for} 12 \mathrm{~h}$. The CDA-II-induced apoptotic percentage, particularly in the early apoptotic cells, was increased in all these human MM cell lines. ${ }^{*} \mathrm{P}<0.01$ and ${ }^{* *} \mathrm{P}<0.05$ vs. the untreated control. The data represent the mean \pm standard deviation of three independent experiments. MM, multiple myeloma; CDA-II, cell differentiation agent II.

5.64 and $3.54 \mathrm{mg} / \mathrm{ml}$, respectively. By contrast, CDA-II did not induce cytotoxicity in PBMCs from three normal volunteers (18). The effect of CDA-II on the RPMI8226, U266 and MM.1R cell lines was evaluated in the presence of exogenous IL-6, which is an important growth factor in MM. Fig. 1B demonstrates that IL-6 $(50 \mathrm{ng} / \mathrm{ml})$ did not provide protection against CDA-II-induced growth inhibition and apoptosis.
CDA-II induces apoptosis of human MM cell lines. To analyze whether CDA-II induced apoptosis of the human MM cell line, the translocation of phosphatidylserine was examined. Non-apoptotic cells revealed neither Annexin V nor PI fluorescence. Annexin $\mathrm{V}^{+} / \mathrm{PI}^{-}$and Annexin $\mathrm{V}^{+} / \mathrm{PI}^{+}$cells represented an early and a late phase of apoptosis, respectively. The percentage of early apoptosis in the RPMI8226 


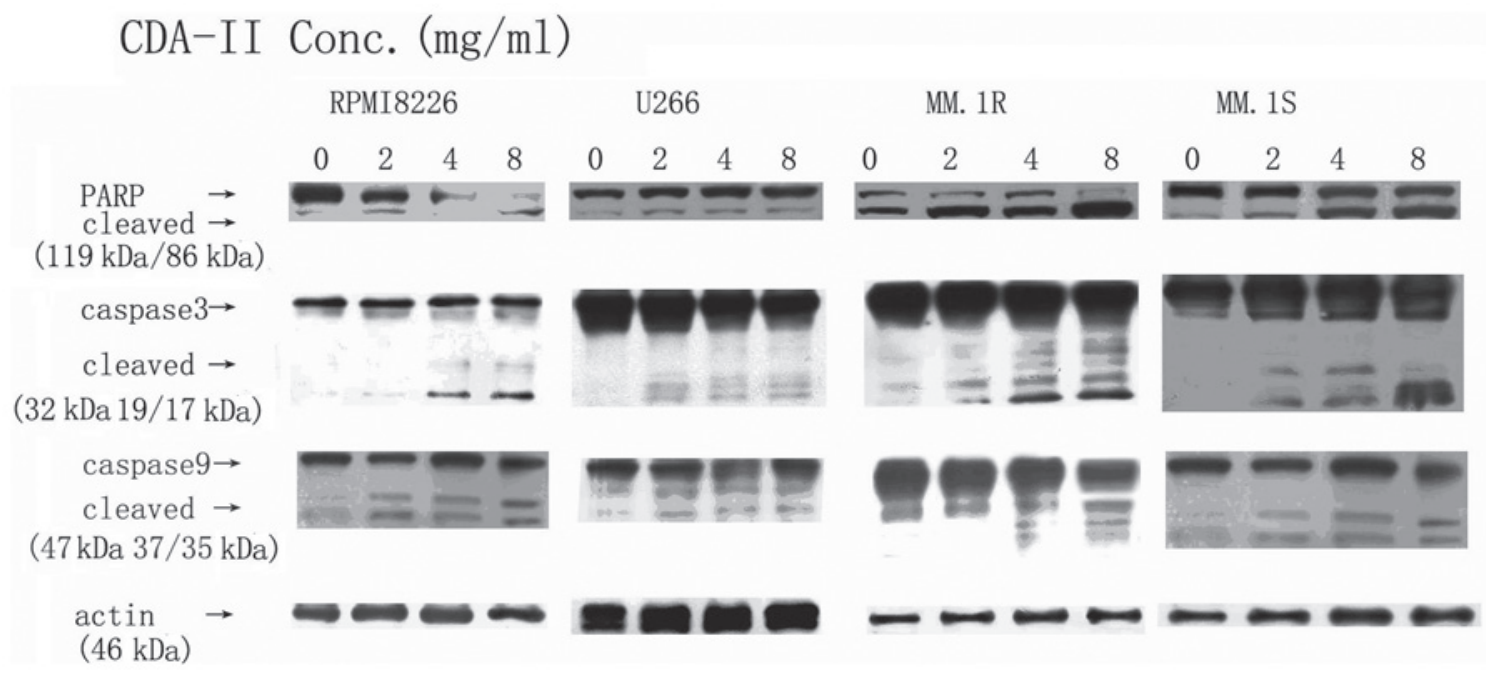

Figure 3. Apoptosis triggered by CDA-II was mediated via the caspase cascades. CDA-II induced dose-dependent activation of caspases-3 and -9 and PARP. Human multiple myeloma RPMI8226, U266, MM.1R, MM.1S cells treated with CDA-II 2-8mg/ml. CDA-II, cell differentiation agent II; PARP, poly (ADP-ribose) polymerase.

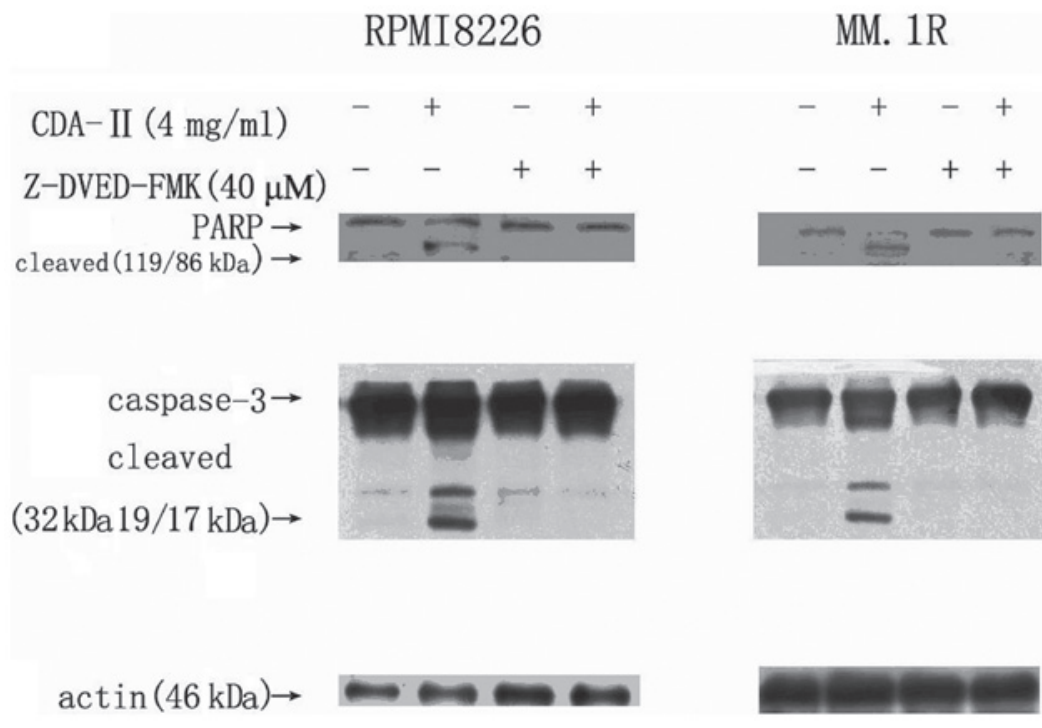

Figure 4. RPMI8226 and MM.1R cells were preincubated with $40 \mu \mathrm{mol} / 1 \mathrm{Z}-\mathrm{DEVD}-\mathrm{fmk}$ for $1 \mathrm{~h}$ prior to the treatment with $4 \mathrm{mg} / \mathrm{ml}$ CDA-II for $24 \mathrm{~h}$. Z-DEVD-fmk completely inhibited CDA-II-induced caspase-3 activation and PARP cleavage. CDA-II, cell differentiation agent II; MM, multiple myeloma; PARP, poly (ADP-ribose) polymerase.

cell lines following treatment by $2-8 \mathrm{mg} / \mathrm{ml} \mathrm{CDA-II} \mathrm{for} 12 \mathrm{~h}$ was increased (Fig. 2A). CDA-II-induced apoptosis was also verified in other human MM cell lines, including the U266, MM.1R and MM.1S cells (Fig. 2B). The findings also indicated that the increase in CDA-II-mediated apoptotic cells occurred in a dose-dependent manner.

Apoptosis triggered by CDA-II is mediated via caspase-3 and -9 and by PARP cleavage, through decreasing the Bcl-2/Bax ratio and Mcl-1 expression. On the basis of the results of MTT and Annexin V/PI staining, the present study attempted to identify the mechanisms of CDA-II-induced cell death in MM cells, and furthermore, the activation of caspase- 3 and -9 and the cleavage of PARP in the RPMI8226, U266, MM.1R and MM.1S cell lines was examined. CDA-II induced activation of caspase- 3 and -9 , and the cleavage of
PARP. The activation of caspase-3 is important in the induction of apoptosis by a variety of stimuli. As demonstrated in Fig. 3, caspase-3 and -9 were noted to be activated in a dose-dependent manner.

An attempt was made to determine whether caspase-3 is important in CDA-II-induced apoptosis by treating the cells with the specific caspase-3 inhibitor, Z-DEVD-FMK (19). The inhibition of caspase-3 activity by pretreatment with $40 \mu \mathrm{mol} / 1$ Z-DEVD-FMK significantly decreased the apoptotic cells of the RPMI8226 and MM.1R cell lines following CDA-II treatment (Fig. 4). These results indicated that CDA-II-induced apoptosis may be caspase-3-dependent.

Since the Bcl-2 family is associated with the activation of caspase-9 and the mitochondrial pathway, the expression of Bcl-2, Bax and Mcl-1 in CDA-II-induced apoptosis was investigated further. Following treatment with $4 \mathrm{mg} / \mathrm{ml}$ CDA-II, 
RPMI8226

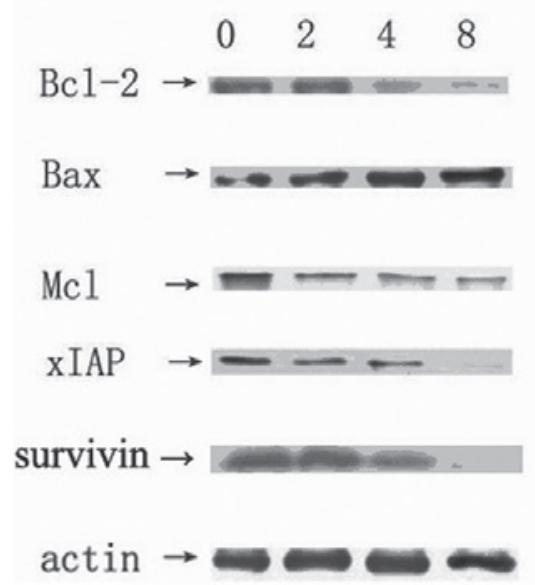

U266
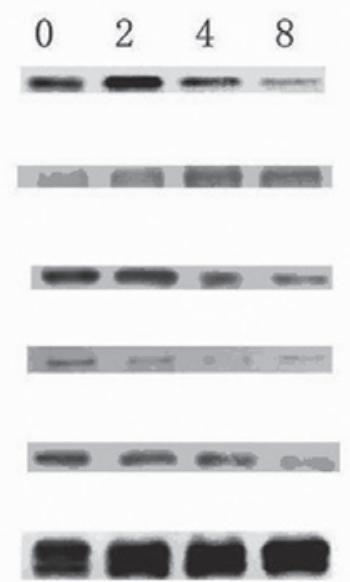

MM. $1 R$

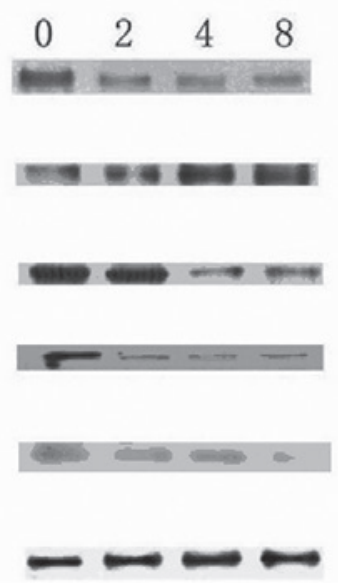

MM. 1S

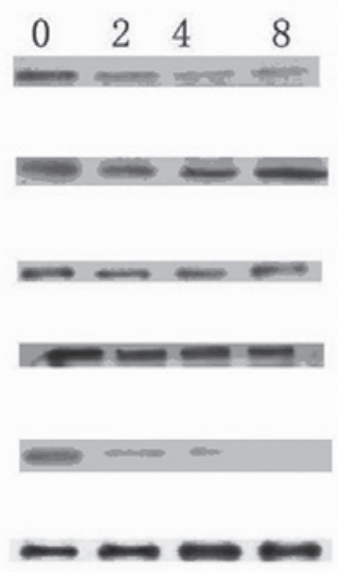

Figure 5. RPMI8226, U266, MM.1R and MM.1S cells were cultured with CDA-II (2, 4 and $8 \mathrm{mg} / \mathrm{ml})$ for $12 \mathrm{~h}$. The total cell lysates were analyzed by western blotting using Bcl-2 (28 kDa), Bax (20 kDa), Mcl-1 (40 kDa), XIAP (53 kDa), survivin (16 kDa) and actin (46 kDa) antibodies. CDA-II, cell differentiation agent II; XIAP, X-linked inhibitor of apoptosis protein.

A

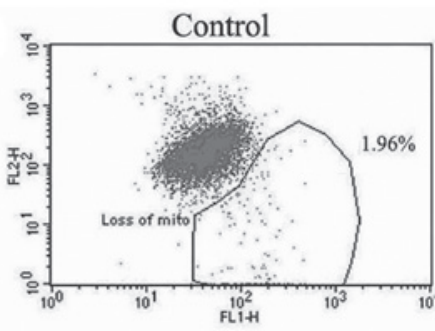

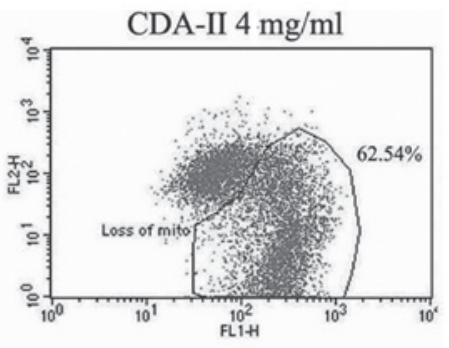

B

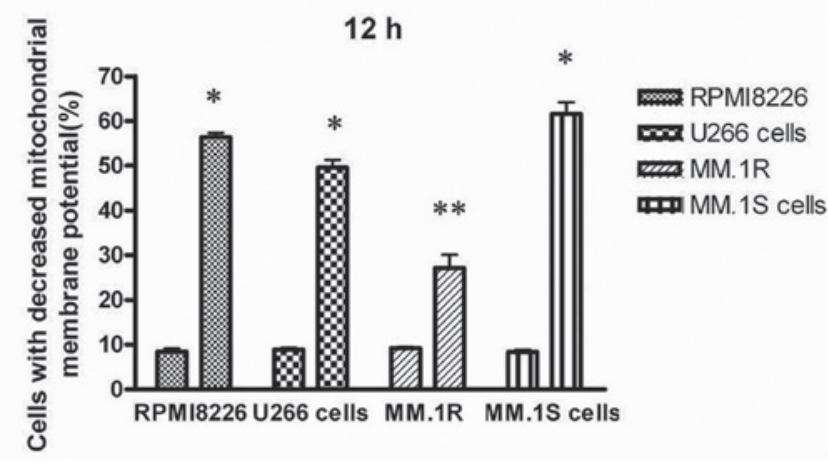

Figure 6. CDA-II induced the change of mitochondrial membrane potential $(\Delta \psi \mathrm{m})$ in four human MM cell lines. Cells were treated with $4 \mathrm{mg} / \mathrm{ml}$ CDA-II for $12 \mathrm{~h}$ and stained with the mitochondria-selective JC-1 dye. The percentage of cells with fluorescence show the corresponding tendency of apoptotic cells. (A) The left image represents the control, the right image represents cells treated with $4 \mathrm{mg} / \mathrm{ml}$ CDA-II. (B) The data represent the mean \pm standard deviation of three independent experiments. " $\mathrm{P}<0.01$ and ${ }^{* *} \mathrm{P}<0.05$ vs. the untreated control. CDA-II, cell differentiation agent II; MM, multiple myeloma.

there was a dose-dependent decrease in the level of Bcl-2 and Mcl-1 protein and a dose-dependent increase in the level of Bax protein $(\mathrm{P}<0.01$; Fig. 5$)$, which activates caspase- 9 by the decrease of the $\mathrm{Bcl}-2 / \mathrm{Bax}$ ratio (Fig. 5) and the downregulation of Mcl-1.

CDA-II inhibits expression of the IAP family, triggering caspase-dependent cell death in human MM cell lines. The Bcl-2 and IAP family proteins regulate mitochondria-mediated apoptosis, and the present study attempted to directly demonstrate that mitochondria are involved in CDA-II-induced apoptosis. Following treatment of the cells with $4 \mathrm{mg} / \mathrm{ml} \mathrm{CDA}-\mathrm{II}$ for $12 \mathrm{~h}$, an increased ratio of cells with depolarized mitochondrial membranes was observed in all the human MM cell lines $(\mathrm{P}<0.01$; Fig. 6), which indicated that the mitochondria were involved in CDA-II-induced apoptosis. CDA-II-induced cell death appears to be caspase dependent, while XIAP is the most potent natural cellular inhibitor of caspases (20), therefore, the effect of CDA-II on XIAP and the survivin protein was examined. Following treatment of 
CDA-II for $12 \mathrm{~h}$, the XIAP and survivin protein levels were significantly decreased in the human MM cell lines in a dose-dependent manner ( $\mathrm{P}<0.01$; Fig. 5).

\section{Discussion}

MM is currently an incurable hematological malignancy, and novel biologically-based treatment strategies for elderly patients and for overcoming conventional drug resistance are urgently required. Previously the medical use of urine preparations in cancer prevention has been studied and various mechanisms have been proposed to explain their effects. Clinically, antineoplastones were prepared from urine by Burzynki (21) and shown to produce objective responses in cancer patients, such as tumor reduction. Antitumor urinary proteins were identified and revealed to possess anticancer activity (22-23). The anticancer activity of CDA-II on acute myeloid leukemia cell lines was also analyzed (18). The components of this urine extract, including endostatin and angiostatin, have been described as potent inhibitors of angiogenesis and malignant growth (24). In the present study, CDA-II, a urinary preparation, was first demonstrated to be capable of inducing apoptosis in the human MM cell lines, RPMI8226, U266, MM.1R and MM.1S, however, it had exhibited no cytotoxicity in the PBMCs from normal volunteers in previous studies $(8,18,25)$. The results of in vitro experiments indicated the potent antitumor activity of CDA-II via the nuclear translocation of the NF- $\mathrm{KB}$ p65 subunit. In the present study, the results indicated that CDA-II induced apoptotic death in a dose-dependent manner in human MM cell lines. Following the incubation of $4 \mathrm{mg} / \mathrm{ml} \mathrm{CDA-II}$ for $12 \mathrm{~h}$, Annexin $\mathrm{V}^{+}$cells were revealed to be associated with cytoplasmic membrane damage, as evaluated by PI staining. Apoptosis was also confirmed by the activation of the caspase cascade, which is a crucial gateway involved in the execution of apoptosis in a variety of cellular systems. It was shown that when the caspase cascade was activated, caspase- 3 disassembled PARP into cleaved fragments. Observations in the present study demonstrated that cleaved caspase- 3 and PARP appeared following incubation of CDA-II $4 \mathrm{mg} / \mathrm{ml}$ for $12 \mathrm{~h}$, which indicated that the activation of the caspase family was correlated with CDA-II-induced apoptosis. The caspase-3 inhibitor, Z-DEVD-FMK ( $40 \mu \mathrm{mol} / \mathrm{l})$, was able to significantly block CDA-II-induced apoptosis in the MM cell lines, which indicated that the activation of caspase- 3 was closely correlated with CDA-II-induced apoptosis.

While the primary cause of treatment failures in MM is the emergence of resistant disease and early relapse, among the most frequent causes of these phenomena are the defects in the mitochondrial-mediated apoptotic pathway (26-27). The expression pattern of the Bcl-2 family of pro-apoptotic and anti-apoptotic genes in MM have been the subject of multiple studies in which it was demonstrated that increased levels of $\mathrm{Bcl}-2, \mathrm{Bcl}-\mathrm{xL}$, and Mcl-1 expression are linked to MM cell survival and resistance to chemotherapeutic agents. This pathway was regulated by the Bcl-2 family of anti-apoptotic (Bcl-2 and Mcl-1) and pro-apoptotic (Bax and Bak) proteins. Bcl-2 functioned as an inhibitor of mitochondrial permeabilization, by changing its conformation on the mitochondrial membrane to affect membrane insertion (28). Overexpression of the anti-apoptotic members has been linked to resistance to various chemotherapeutic agents.
Following exposure to chemotherapeutic agents, increased expression of these proteins of the MM cell lines indicated that these agents may contribute to acquired chemoresistance. Thus, we suggest that regulation of anti-apoptotic proteins may be a significant strategy for sensitizing MM cells to various therapeutic agents. In the present study, CDA-II determined a strong and rapid downregulation of $\mathrm{Bcl}-2$ and an upregulation of Bax, decreasing the $\mathrm{Bcl}-2 / \mathrm{Bax}$ ratio, thus indicating that this may present a novel therapeutic regimen, capable of inducing apoptosis at an early treatment state. CDA-II also overcame the multidrug resistance in vivo. These results indicated that CDA-II induced apoptosis in the human MM cell lines through the mitochondria-mediated pathway.

The findings of this study confirmed that CDA-II downregulated XIAP and Mcl-1 expression, potently inhibited cell growth and promoted cell death through the mitochondrial pathway in various $\mathrm{MM}$ cells, including the dexamethasone-resistant MM cell line. Mcl-1 is a member of the anti-apoptotic Bcl-2 family of proteins that inhibit cell death at the mitochondrial level. Mcl-1 downregulation and cleavage has been shown to induce apoptosis of tumor cells (29-30). Furthermore, Mcl-1 acts not only as an anti-apoptotic protein that opposes drug-induced apoptosis, but also as a pro-apoptotic cleaved protein enhancing mitochondrial/caspase activation and thereby leading to apoptosis (31). Furthermore, XIAP may be involved in worsening the prognosis of MM patients in association with the chemotherapy-induced overexpression of multidrug- or lung-resistance proteins (32). Survivin is also a notable member of the IAP family, with dual roles in mitosis and apoptosis. The data of the present study demonstrated that the expression of XIAP and survivin was decreased during CDA-II-induced apoptosis. Since Mcl-1, Bcl-2 and XIAP are frequently overexpressed in MM cells (33), the ability of CDA-II to reduce the levels of Mcl-1 and XIAP rendered it a powerful inducer of apoptosis and overcoming the multidrug resistance. By decreasing XIAP and Mcl-1, CDA-II may also lower the apoptotic threshold and thereby enhance cell death induced by chemotherapeutic agents.

In conclusion, this study provided evidence that CDA-II induced the significant cytotoxicity of MM cells, particularly drug resistant MM cells, in vitro. The results of this study provide evidence supporting the use of CDA-II as a novel $\mathrm{NF}-\kappa \mathrm{B}$ inhibitor with marked anti-MM efficacy in vitro. The potent effects of CDA-II in MM cells and its moderate effect reported in this study provided a rational method, particularly for elderly patients.

\section{Acknowledgements}

This study was supported by the National Natural Science Foundation of China (grant no. 81101792), the Science Research Foundation of Chinese Traditional Medicine of Zhejiang Province (grant no. 2011ZB064) and the Research Fund for the Doctoral Program of Higher Education of China (grant no. 20110101120105).

\section{References}

1. Gregory WM, Richards MA and Malpas JS: Combination chemotherapy versus melphalan and prednisolone in the treatment of multiple myeloma: an overview of published trials. J Clin Oncol 10: 334-342, 1992. 
2. Lenhoff S, Hjorth M, Holmberg E, et al: Impact on survival of high-dose therapy with autologous stem cell support in patients younger than 60 years with newly diagnosed multiple myeloma: a population-based study. Nordic Myeloma Study Group. Blood 95: 7-11, 2000.

3. Attal M, Harousseau JL, Facon T, et al; InterGroupe Francophone du Myélome: Single versus double autologous stem-cell transplantation for multiple myeloma. N Engl J Med 349: 2495-2502, 2003.

4. Sonneveld P: Drug resistance in multiple myeloma. Pathol Biol (Paris) 47: 182-187, 1999.

5. Covelli A: Modulation of multidrug resistance (MDR) in hematological malignancies. Ann Oncol 10 (Suppl 6): 53-59, 1999.

6. Schwarzenbach H: Expression of MDR1/P-glycoprotein, the multidrug resistance protein MRP, and the lung-resistance protein LRP in multiple myeloma. Med Oncol 19: 87-104, 2002.

7. Burzynski SR: Antineoplastons: history of the research (I) Drugs Exp Clin Res 12 (Suppl 1): 1-9, 1986.

8. Badria F, Mabed M, Khafagy W and Abou-Zeid L: Potential utility of antineoplaston A-10 levels in breast cancer. Cancer Lett 155: 67-70, 2000.

9. Lin WC, Wu YW, Lai TY and Liau MC: Effect of CDA-II, urinary preparation, on lipofuscin, lipid peroxidation and antioxidant systems in young and middle-aged rat brain. Am J Chin Med 29: 91-99, 2001

10. Masood R, McGarvey ME, Zheng T, Cai J, Arora N, Smith DL, Sloane N and Gill PS: Antineoplastic urinary protein inhibits Kaposi's sarcoma and angiogenesis in vitro and in vivo. Blood 93: 1038-1044, 1999.

11. Yao CJ, Lai GM, Chan CF, Yang YY, Liu FC and Chuang SE: Differentiation of pheochromocytoma PC12 cells induced by human urine extract and the involvement of the extracellular signal-regulated kinase signaling pathway. J Altern Complement Med 11: 903-908, 2005.

12. Liau MC, Szopa M, Burzynski B and Burzynski SR: Quantitative assay of plasma and urinary peptides as an aid for the evaluation of cancer patients undergoing antineoplaston therapy. Drugs Exp Clin Res 13 (Suppl 1): 61-70, 1987.

13. Sun JJ, Zhou Xd and Liu YK: Effect of CDA-II on prevention and therapy for metastasis and recurrence of liver cancer in nude mice. Chin J Hepatobiliary Surg 546-551, 2006 (In Chinese).

14. Sun L, Huang Q, Wang A, Lan Q, Du Z and Hu G: cDNA array in the establishment of a gene expression profile associated with differentiation inducing the glioma cells. Zhonghua Zhong Liu Za Zhi 24: 222-225, 2002 (In Chinese).

15. Wang YH and Zheng WI: Effects of uroacitides on proliferation ability of breast cancer cells. Chinese Journal of Clinical Pharmacology and Therapeutics 10: 677-681, 1999 (In Chinese).

16. Lin WC, Liao YC, Liau MC, Lii CK and Sheen LY: Inhibitory effect of CDA-II, a urinary preparation, on aflatoxin $\mathrm{B}(1)$-induced oxidative stress and DNA damage in primary cultured rat hepatocytes. Food Chem Toxicol 44: 546-551, 2006

17. Chen Z, Jin G, Lin S, Lin X, Gu Y, Zhu Y, Hu C, Zhang Q, Wu L and Shen H: DNA methyltransferase inhibitor CDA-II inhibits myogenic differentiation. Biochem Biophys Res Commun 422: 522-526, 2012.

18. Huang J, Yang M, Liu H and Jin J: Human urine extract CDA-2 induces apoptosis of myelodysplastic syndrome-derived MUTZ-1 cells through the PI3K/Akt signaling pathway in a caspase-3-dependent manner. Acta Pharmacol Sin 29: 951-964, 2008.
19. Fischer U and Schulze-Osthoff K: Apoptosis-based therapies and drug targets. Cell Death Differ 12 (Suppl 1): 942-961, 2005

20. Carter BZ, Mak DH, Schober WD, McQueen T, Harris D, Estrov Z, Evans RL and Andreeff M: Triptolide induces caspase-dependent cell death mediated via the mitochondrial pathway in leukemic cells. Blood 108: 630-637, 2006.

21. Burzynski SR: The present state of antineoplaston research (1). Integr Cancer Ther 3: 47-58, 2004.

22. Hehir KM, Baguisi A, Pennington SE, Bates JM and DiTullio PA: A potential antitumor peptide therapeutic derived from antineoplastic urinary protein. Peptides 25: 543-549, 2004.

23. Lakhani NJ, Sparreboom A, Xu X, Veenstra TD, Venitz J, Dahut WL and Figg WD: Characterization of in vitro and in vivo metabolic pathways of the investigational anticancer agent, 2-methoxyestradiol. J Pharm Sci 96: 1821-1831, 2007.

24. Linder-Stragliotto C, Strander H, Munck-Wikland E and Sten-Linder M: Low levels of endostatin in the urine from patients with malignant disease. Tumour Biol 23: 222-227, 2002.

25. Huang J, Yang M, Liu H and Jin J: CDA-II, a urinary preparation, induces growth arrest and apoptosis of human leukemia cells through inactivation of nuclear factor-kappaB in a caspasedependent manner. Food Chem Toxicol 47: 40-49, 2009.

26. Zhang B, Gojo I and Fenton RG: Myeloid cell factor-1 is a critical survival factor for multiple myeloma. Blood 99: 1885-1893, 2002.

27. Tu Y, Renner S, Xu F, et al: BCL-X expression in multiple myeloma: possible indicator of chemoresistance. Cancer Res 58: 256-262, 1998.

28. Bharti AC, Shishodia S, Reuben JM, et al: Nuclear factor-kappaB and STAT3 are constitutively active in CD138 ${ }^{+}$ cells derived from multiple myeloma patients, and suppression of these transcription factors leads to apoptosis. Blood 103 : 3175-3184, 2004

29. Gomez-Bougie P, Wuillème-Toumi S, Ménoret E, Trichet V, Robillard N, Philippe M, Bataille R and Amiot M: Noxa up-regulation and Mcl-1 cleavage are associated to apoptosis induction by bortezomib in multiple myeloma. Cancer Res 67: 5418-5424, 2007.

30. Han J, Goldstein LA, Gastman BR and Rabinowich H: Interrelated roles for Mcl-1 and BIM in regulation of TRAIL-mediated mitochondrial apoptosis. J Biol Chem 281: 10153-10163, 2006.

31. Podar K, Gouill SL, Zhang J, Opferman JT, Zorn E, Tai YT, Hideshima T, Amiot M, Chauhan D, Harousseau JL and Anderson KC: A pivotal role for Mcl-1 in Bortezomib-induced apoptosis. Oncogene 27, 721-731, 2008.

32. Nakagawa $Y$, Abe S, Kurata M, Hasegawa M, Yamamoto $K$, Inoue M, Takemura T, Suzuki K and Kitagawa M: IAP family protein expression correlates with poor outcome of multiple myeloma patients in association with chemotherapy-induced overexpression of multidrug resistance genes. Am J Hematol 81: 824-831, 2006

33. Spets H, Strömberg T, Georgii-Hemming P, Siljason J, Nilsson K and Jernberg-Wiklund H: Expression of the bcl-2 family of pro- and anti-apoptotic genes in multiple myeloma and normal plasma cells: regulation during interleukin-6(IL-6)-induced growth and survival. Eur J Haematol 69: 76-89, 2002. 